\title{
Rapid growth of tin whiskers on the surface of $\mathrm{Sn-6.6Lu}$ alloy
}

\author{
T.H. Chuang, ${ }^{*}$ H.J. Lin and C.C. Chi \\ Institute of Materials Science and Engineering, National Taiwan University, Taipei 106, Taiwan \\ Received 6 June 2006; revised 18 August 2006; accepted 26 August 2006 \\ Available online 5 October 2006
}

\begin{abstract}
During the storage of a Sn-6.6Lu alloy in air for several days, large amounts of thread-like tin whiskers appear on the oxidized surface of $\mathrm{Lu}_{4} \mathrm{Sn}_{5}$ precipitates in this alloy. Storage at $150{ }^{\circ} \mathrm{C}$ for $30 \mathrm{~min}$ causes hillock-type whiskers to form. The driving force for whisker growth in this $\mathrm{Sn}-6.6 \mathrm{Lu}$ alloy is the compressive stress resulting from the diffusion of oxygen into the lattice of the $\mathrm{Lu}_{4} \mathrm{Sn}_{5}$ precipitates.
\end{abstract}

(C) 2006 Acta Materialia Inc. Published by Elsevier Ltd. All rights reserved.

Keywords: Sn-6.6Lu; Rare-earth element; Tin whiskers; Hillocks

The formation of tin whiskers on electrodeposited Sn and Sn-alloys has been acknowledged for over 50 years [1]. Tin whiskers were found to be single crystals with a typical length of a few hundred micrometers which sprout from the Sn matrix and can get kinked during the growth process. Typical growth rates of tin whiskers in a bulk material are about $0.01-0.1 \AA \mathrm{s}^{-1}$ [2]. However, some cases with more rapid growth rates have been reported. Tin whiskers were observed by Furuta and Hamaura to grow in a rapidly cooled $\mathrm{Al}-50 \% \mathrm{Sn}$ film at rates of about $0.5-5 \AA^{-1}$ [3]. Higher whisker growth rates of about 2-4 $\AA^{-1}$ were found in electroplated Sn-Mn films [4]. Liu et al. reported that tin whisker growth can be accelerated to $3 \AA \mathrm{s}^{-1}$ with an electrical current density of $1.5 \times 10^{5} \mathrm{~A} \mathrm{~cm}^{-2}$ [5]. They also found that the whisker growth rates increase with rising temperature.

Several models for the growth mechanism of tin whiskers, including dislocation theory [6] and recrystallization theory [3], have been proposed. However, other researchers have reported that tin whisker growth is related to the outer oxide layer on the Sn surface and the internal compressive stress in the Sn matrix. Tu studied the tin whiskers on a bimetallic $\mathrm{Cu}-\mathrm{Sn}$ thin-film specimen and proposed the existence of a biaxial compressive stress produced in $\mathrm{Sn}$ film accompanying $\mathrm{Cu}_{6} \mathrm{Sn}_{5}$ formation, which drives the extrusion of the whiskers from the outer oxide layer [7]. Sheng et al. further suggested that whiskers sprout from weaker spots of the oxide layer on

\footnotetext{
* Corresponding author. E-mail: tunghan@ntu.edu.tw
}

the Sn surface and that the roots of whiskers become localized stress relief centers [8].

It is known that rare-earth elements exhibit high chemical activity. Sn alloys containing rare-earth elements should readily form an oxide layer that can give rise to the growth of tin whiskers. This study presents the effect of rare-earth elements on tin whisker growth in a $\mathrm{Sn}-6.6 \mathrm{Lu}$ solder alloy.

For the preparation of the $\mathrm{Sn}-6.6 \mathrm{Lu}$ alloy, pure $\mathrm{Sn}$ $(99.9 \%)$ and pure $\mathrm{Lu}(99.9 \%)$ were melted at $1000{ }^{\circ} \mathrm{C}$ under a $10^{-5}$ Torr vacuum. The as-cast specimens were cut with a diamond saw, and their cross sections were ground with 2000 grit $\mathrm{SiC}$ paper and polished with $0.3 \mu \mathrm{m} \mathrm{Al}{ }_{2} \mathrm{O}_{3}$ powder. Some specimens were stored at room temperature in air, while others were aged at $150^{\circ} \mathrm{C}$ in an air furnace. After various storage periods, the morphology of the tin whiskers that formed on the surface was observed by scanning electron microscopy (SEM). The chemical composition of the specimens was analyzed using an electron probe microanalyzer (EPMA).

The microstructure of the as-cast $\mathrm{Sn}-6.6 \mathrm{Lu}$ alloy contains many large precipitates, as shown in Figure 1(a). EPMA analysis indicates that the composition (at.\%) of these precipitates is $\mathrm{Lu}: \mathrm{Sn}=44.4: 55.6$, which corresponds to the $\mathrm{Lu}_{4} \mathrm{Sn}_{5}$ phase. Figure 1(b) reveals that after storage at room temperature in air for $4 \mathrm{~h}$, the surface of the $\mathrm{Lu}_{4} \mathrm{Sn}_{5}$ is covered with many bright particles, and its chemical composition (at.\%) changes to $\mathrm{Lu}$ : $\mathrm{Sn}: \mathrm{O}=37.2: 29.3: 33.5$. This result indicates that the $\mathrm{Lu}_{4} \mathrm{Sn}_{5}$ precipitates have oxidized much more rapidly than the matrix of the $\mathrm{Sn}-6.6 \mathrm{Lu}$ alloy. The bright 

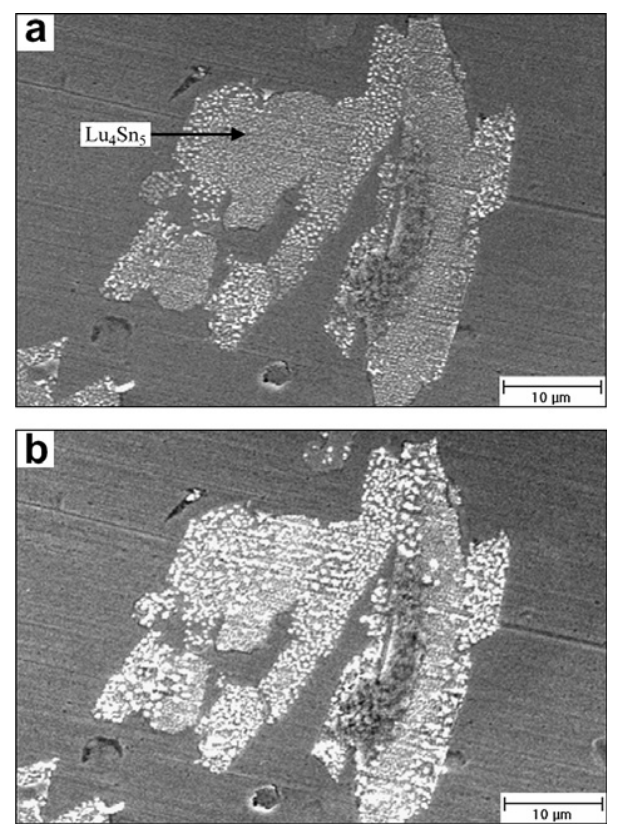

Figure 1. Morphology of $\mathrm{Lu}_{4} \mathrm{Sn}_{5}$ precipitates with tin particles distributed in $\mathrm{Sn}-6.6 \mathrm{Lu}$ alloy after air storage at room temperature for short periods: (a) $10 \mathrm{~min}$, (b) $240 \mathrm{~min}$.

particles are composed of nearly pure Sn, which implies that they are the sprouts of tin whiskers. With a further increase of the storage time to over 2 days, many threadlike whiskers appear in the oxidized $\mathrm{Lu}_{4} \mathrm{Sn}_{5}$ precipitation region, as shown in Figure 2(a). Some whiskers grow very quickly to a length of over $45 \mu \mathrm{m}$ with an increase of storage time, as can be seen in Figure 2(b). The maximal growth rate of tin whiskers for the case of room-temperature storage in air is about $1 \AA \mathrm{s}^{-1}$.
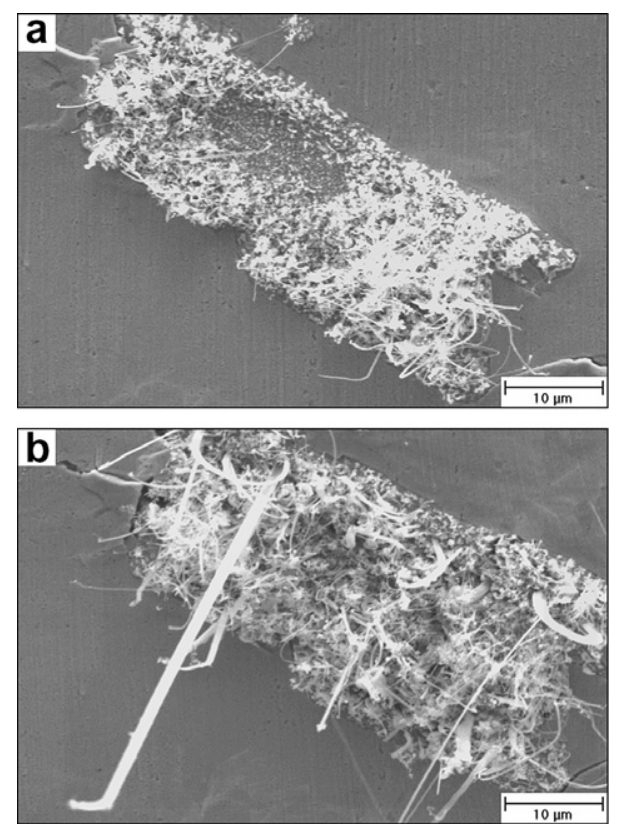

Figure 2. Thread-like tin whiskers formed on the surface of $\mathrm{Lu}_{4} \mathrm{Sn}_{5}$ precipitates in $\mathrm{Sn}-6.6 \mathrm{Lu}$ alloy after air storage at room temperature for long periods: (a) $48 \mathrm{~h}$, (b) $240 \mathrm{~h}$.
When the storage temperature is raised to $150{ }^{\circ} \mathrm{C}$, tin whiskers form much earlier, as compared to the samples stored at room temperature. Figure 3(a) shows that some whiskers grew to a length of about $30 \mu \mathrm{m}$ in the sample that was stored at $150{ }^{\circ} \mathrm{C}$ for only $10 \mathrm{~min}$. The whisker growth rate in this case reaches about $500 \AA \mathrm{A} \mathrm{s}^{-1}$. Such rapid and early growth of tin whiskers has never been reported previously in the literature. When the storage time is increased, a few hillock-type whiskers coexist with the thread-like whiskers in the oxidized $\mathrm{Lu}_{4} \mathrm{Sn}_{5}$ region, as shown in Figure 3(b). A long period of storage at $150^{\circ} \mathrm{C}$ in air causes further growth of both the thread-like and hillock-type whiskers in the oxidized $\mathrm{Lu}_{4} \mathrm{Sn}_{5}$ region (Fig. 4). It can be seen in Figure 4(a) that more than $500 \mu^{3}$ of tin has been extruded out of the $\mathrm{Lu}_{4} \mathrm{Sn}_{5}$ precipitate in the micrograph after storage at $150{ }^{\circ} \mathrm{C}$ for $112 \mathrm{~h}$ through the growth process of hillock-type whiskers. In contrast, whisker growth was obviously reduced when the specimens were stored at room temperature for 3 days and at $150{ }^{\circ} \mathrm{C}$ for $2 \mathrm{~h}$ in a vacuum furnace of $10^{-3}$ Torr as illustrated in Figure 5 (a) and (b), respectively. The results imply that the formation of tin whiskers in this $\mathrm{Sn}-6.6 \mathrm{Lu}$ alloy is closely related to the oxidation of $\mathrm{Lu}_{4} \mathrm{Sn}_{5}$ precipitates.

In order to clarify the mechanism for whisker growth in this rare-earth-Sn alloy, specimens were cut across the $\mathrm{Lu}_{4} \mathrm{Sn}_{5}$ precipitates. The three-dimensional cross section in Figure 6(a) reveals a continuous oxide layer with a thickness of about $2 \mu \mathrm{m}$ on the outer surface of a $\mathrm{Lu}_{4} \mathrm{Sn}_{5}$ precipitate in the $\mathrm{Sn}-6.6 \mathrm{Lu}$ stored at room temperature for $4 \mathrm{~h}$. The diffusion rate of oxygen, as estimated from the thickness of the oxide layer, is about $1.4 \AA^{-1}$. The chemical composition (at.\%) of the outer oxide layer is $\mathrm{Lu}: \mathrm{Sn}: \mathrm{O}=30.9: 35.1: 34.0$, which is similar to that analyzed for the surfaces of $\mathrm{Lu}_{4} \mathrm{Sn}_{5}$ phase in Figure 1(b), However, Figure 6(b) shows that in the specimen stored at $150^{\circ} \mathrm{C}$ for $90 \mathrm{~min}$, the oxygen
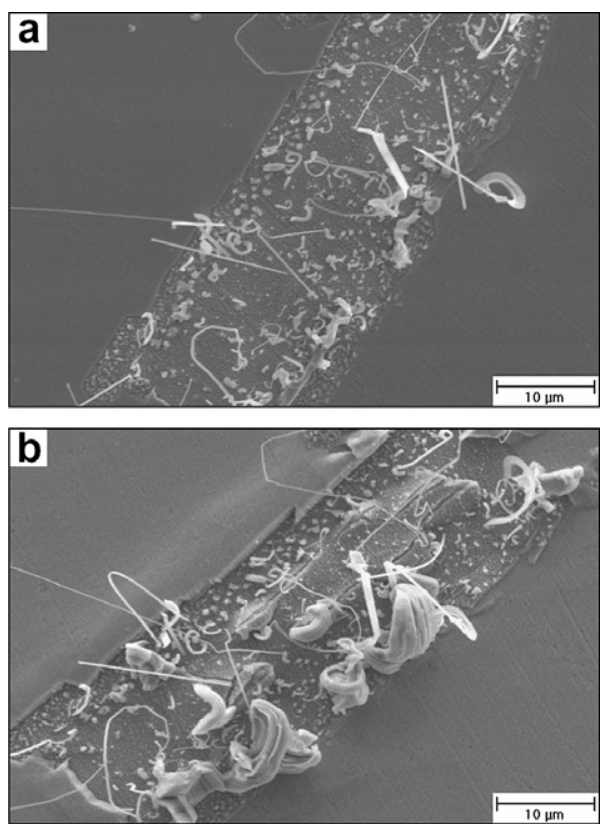

Figure 3. Hillock-type tin whiskers formed on the surface of $\mathrm{Lu}_{4} \mathrm{Sn}_{5}$ precipitates in $\mathrm{Sn}-6.6 \mathrm{Lu}$ alloy after air storage at $150^{\circ} \mathrm{C}$ for short periods: (a) $10 \mathrm{~min}$, (b) $90 \mathrm{~min}$. 

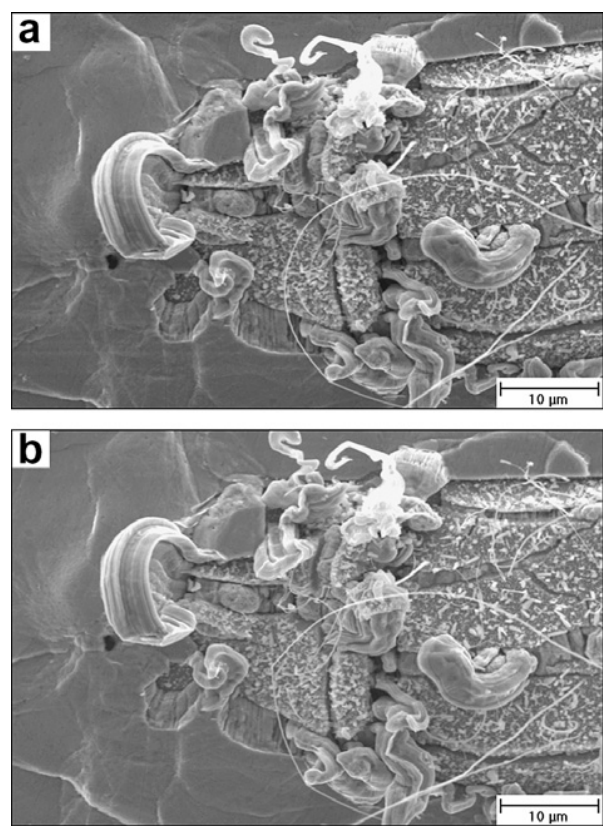

Figure 4. Hillock-type tin whiskers formed on the surface of $\mathrm{Lu}_{4} \mathrm{Sn}_{5}$ precipitates in $\mathrm{Sn}-6.6 \mathrm{Lu}$ alloy after air storage at $150{ }^{\circ} \mathrm{C}$ for long periods: (a) $112 \mathrm{~h}$, (b) $224 \mathrm{~h}$.
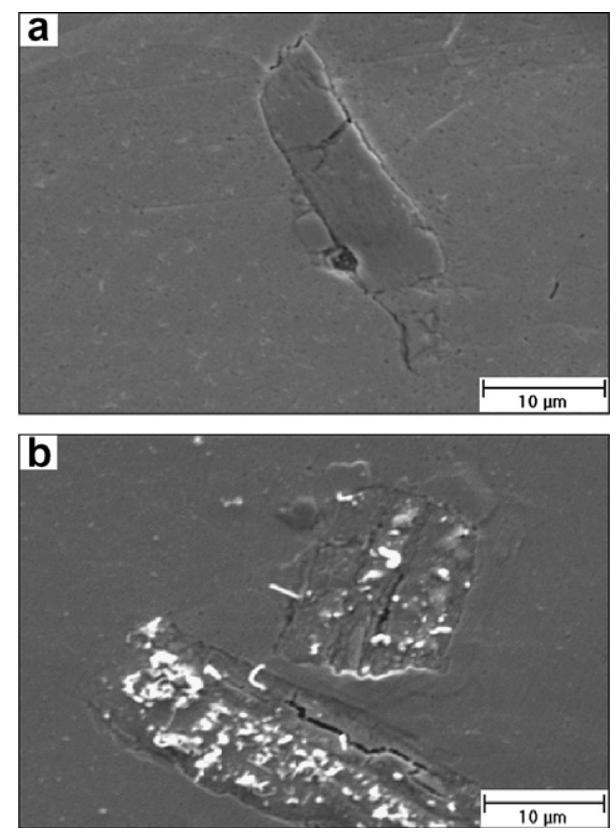

Figure 5. Morphology of $\mathrm{Lu}_{4} \mathrm{Sn}_{5}$ precipitates in $\mathrm{Sn}-6.6 \mathrm{Lu}$ alloy after storage in a vacuum furnace of $10^{-3}$ Torr: (a) at room temperature for 3 days, (b) at $150^{\circ} \mathrm{C}$ for $120 \mathrm{~min}$.

penetrated through the $\mathrm{Lu}_{4} \mathrm{Sn}_{5} / \mathrm{Sn}-6.6 \mathrm{Lu}$ interface to form a thick oxide layer of about $5 \mu \mathrm{m}$ thickness on the outer surface and around the $\mathrm{Lu}_{4} \mathrm{Sn}_{5}$ phase in the interior of the specimen, which corresponds to a diffusion rate of about $10 \mathrm{~A} \mathrm{~s}^{-1}$ for the oxygen into the $\mathrm{Lu}_{4} \mathrm{Sn}_{5}$ phase. EPMA analysis indicates that the enveloped oxide layer possesses a composition (at.\%) of $\mathrm{Lu}$ : $\mathrm{Sn}: \mathrm{O}=51.3: 5.9: 42.8$. The results imply that the $\mathrm{Lu}_{4} \mathrm{Sn}_{5}$ precipitates react predominantly with oxygen to form an
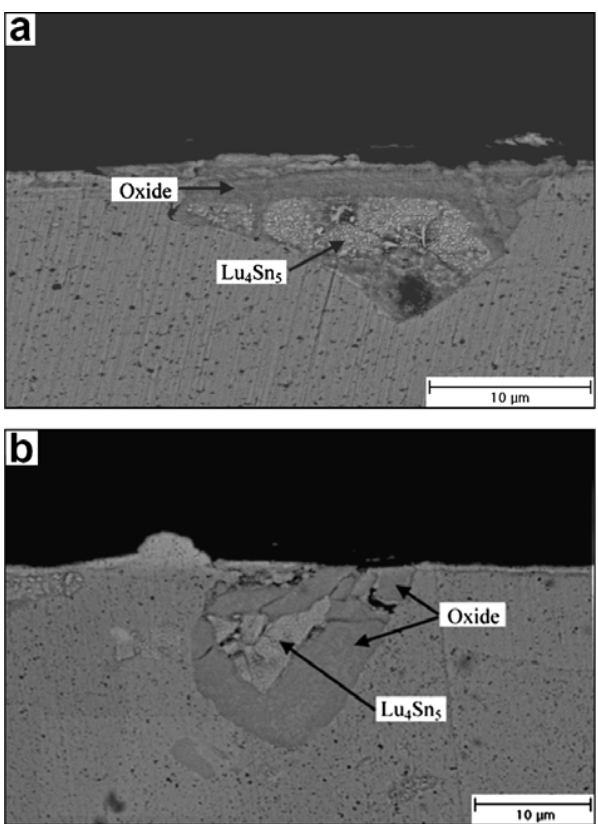

Figure 6. Three-dimensional cross section of $\mathrm{Lu}_{4} \mathrm{Sn}_{5}$ precipitates in $\mathrm{Sn}-6.6 \mathrm{Lu}$ alloy after storage in air: (a) at room temperature for $4 \mathrm{~h}$, (b) at $150{ }^{\circ} \mathrm{C}$ for $90 \mathrm{~min}$.

LuO layer due to the high activity of the Lu element: $2 \mathrm{Lu}_{4} \mathrm{Sn}_{5}+\mathrm{O}_{2} \rightarrow 8 \mathrm{LuO}+10 \mathrm{Sn}$. The diffusion of oxygen into the crystal lattice of the $\mathrm{Lu}_{4} \mathrm{Sn}_{5}$ phase leads to lattice expansion, which is constrained by the surrounding matrix. A compressive stress can be created, which extrudes the resulting $\mathrm{Sn}$ atoms after oxidation out of the surface of the $\mathrm{Lu}_{4} \mathrm{Sn}_{5}$ phase. During storage at room temperature, $\mathrm{Sn}$ atoms in smaller quantities are extruded from the weak spots of the $\mathrm{LuO}$ layer to form threadlike whiskers that are uniformly distributed over the whole surface of the $\mathrm{Lu}_{4} \mathrm{Sn}_{5}$ phase. In this case, a higher Sn concentration of above 30 at.\% was detected in the outer oxide layer. In contrast, large amounts of $\mathrm{Sn}$ atoms in the $\mathrm{LuO}$ around the $\mathrm{Lu}_{4} \mathrm{Sn}_{5}$ phase have been extruded to form hillock-type whiskers, and the Sn concentration in the enveloped $\mathrm{LuO}$ layer drops to a minor value of 5.9 at. $\%$.

In conclusion, after storage at room temperature in air for several days, thread-like whiskers appear on the surface of $\mathrm{Lu}_{4} \mathrm{Sn}_{5}$ precipitates in $\mathrm{Sn}-6.6 \mathrm{Lu}$ solder alloy. The maximal growth rate of tin whiskers in this case is about $1 \AA \mathrm{s}^{-1}$. In contrast, no whiskers can be found in the $\mathrm{Sn}-6.6 \mathrm{Lu}$ matrix. During air storage at $150{ }^{\circ} \mathrm{C}$, the thread-like whiskers grow to a length of about $30 \mu \mathrm{m}$ in $10 \mathrm{~min}$, which corresponds to an amazingly high growth rate of $500 \AA \mathrm{A} \mathrm{s}^{-1}$. After $30 \mathrm{~min}$, hillocktype whiskers coexist with the thread-like whiskers in the $\mathrm{Lu}_{4} \mathrm{Sn}_{5}$ region of $\mathrm{Sn}-6.6 \mathrm{Lu}$ alloy. The rapid growth of tin whiskers in this rare-earth-element-containing alloy is attributed to the predominant oxidation of $\mathrm{Lu}$ atoms, which possess high chemical activity. The oxidation reaction results in the release of Sn atoms, which are inserted in the $\mathrm{LuO}$ layer. The diffusion of oxygen into the $\mathrm{Lu}_{4} \mathrm{Sn}_{5}$ phase leads to a compressive stress, which extrudes the resulting tin atoms out of the $\mathrm{LuO}$ layer. 
This work was sponsored by the National Science Council, Taiwan, under Grant No. NSC-94-2216E002-015.

[1] C. Herring, J.K. Galt, Phys. Rev. 85 (6) (1952) 1060.

[2] W.C. Ellis, D.F. Gibbons, R.C. Treuting, in: R.H. Doremus, B.W. Roberts, D. Turnbull (Eds.), Growth and Perfection of Crystals, John Wiley, New York, NY, 1958.
[3] N. Furuta, K. Hamamura, Jpn. J. Appl. Phys. 8 (12) (1969) 1404.

[4] K. Chen, G.D. Wilcox, Phys. Rev. Lett. 94 (2005) 066104.

[5] S.H. Liu, C. Chen, P.C. Liu, T. Chou, J. Appl. Phys. 95 (12) (2004) 7742

[6] G.T. Galyon, IEEE Trans. Electron. Package. Manuf. 28 (1) (2005) 94.

[7] K.N. Tu, Acta Metall. 21 (4) (1973) 347.

[8] G.T.T. Sheng, C.F. Hu, W.J. Choi, K.N. Tu, Y.Y. Bong, L. Nguyen, J. Appl. Phys. 92 (2002) 64. 